The Crime of Choice: Abortion Border Crossings from Chile to Peru

\author{
Cordelia Freeman
}

School of Geography, University of Nottingham, Nottingham, UK

Citation: Freeman, C. (Forthcoming) The Crime of Choice: Abortion Border Crossings from Chile to Peru. Gender, Place \& Culture 


\section{The Crime of Choice: Abortion Border Crossings from Chile to Peru}

Since 1989 abortion in Chile has been illegal in every single circumstance. This means that tens of thousands of women every year undergo clandestine abortions at great risk to their health. Class directly influences Chilean women's relationships to abortion; wealthier women can pay for the confidentiality of a safe doctor whereas poorer women cannot. There is just one region where women regardless of class can easily travel to another country in search of abortions, Arica in northern Chile. This paper considers the previously unstudied phenomenon whereby women cross the border quickly and cheaply from northern Chile to the Peruvian city of Tacna where numerous clinics offer the procedure. This paper utilises Foucault's concept of biopolitics to trace how women are forced to cross a border to avoid government legislation and finds that even by leaving the territory of the state, women do not fully leave state control. Despite the lack of official statistics, interviews with healthworkers and a young woman who made the crossing show that abortion border crossings do occur and this paper reflects on the legal, safety, and biopolitical ramifications of these journeys for Chilean women.

Keywords: abortion; reproductive rights; biopolitics; Chile, Peru, border crossings 


\section{Introduction}

In 2015 three striking videos racked up views and were shared across Chile and the world. Each showed a different woman telling the viewer how best to induce an abortion that would appear to be an accident. One walks out in front of a car, one falls over a fire hydrant, and one falls down a flight of stairs. The words 'In Chile an accidental abortion is the only kind of abortion that is not considered a crime' appear. These shocking videos were the creation of NGO Miles Chile and advertising agency Grey Chile to contest Chile's draconian reproductive rights whereby abortion is illegal in every single circumstance.

In March 2016, under pressure from international groups including the United Nations, the lower house of Congress in Chile voted to legalise abortion in three cases: risk to the life of the mother, nonviability of the foetus, and rape. While it appears likely that the bill will also pass the Senate to become law in 2017, the vast majority of Chilean women seeking to end their pregnancy will remain unaffected. The abortion tutorial videos illustrate how reproductive control in Chile has been overtly contested yet thousands of women every year are still faced with the reality of choosing between continuing with a pregnancy that they cannot have or do not want or committing a crime by ending it.
This paper discusses how Chilean women are controlled through abortion legislation but also how they have resisted this governing of their bodies through travel. Far from organised viral campaigns, women are making extremely personal, lifechanging decisions that abstract them from their home and lawfulness. This paper posits that the Chilean state wields social and political power over the health of the inhabitants of the Chilean northern borderlands, with violent repercussions. The state exerts biopolitical power over its citizens but the border can become a space of resistance and opportunity even if never a total escape from the state. The aim of this paper is to use the concept of biopolitics to analyse how the governing of women's bodies forces them into certain spatial movements, namely the crossing of international borders for abortion services.

\section{Biopolitical Control}

Following the work of the French philosopher Michel Foucault, biopolitics is a term denoting social and political power over life and was first discussed during his lecture series Society Must Be Defended given at the Collège de France in 1975 and 1976. For Foucault $(1976,252)$, in the nineteenth century 'power took possession of life' through technologies of discipline and regulation which resulted in the biopolitical control of whole populations. Foucault (2003, 242) described biopolitics 
as 'a new technology of power...[that] exists at a different level, on a different scale, and [that] has a different bearing area, and makes use of very different instruments'. To fully understand what he meant by this technology of power it is helpful to understand his wider work on governmentality, biopower, and discipline.

Foucault's (1978) use of 'governmentality' provides a useful lens through which to analyse the governing system that was established by General Augusto Pinochet's military government in Chile (1973-1990) and remains highly influential and, to a large extent, unchanged today. Moreover, Foucault's terms 'biopower' and 'discipline' allow us to understand why women react in certain ways to Chilean reproductive biopolitical control. Governmentality, in its most basic description, refers to the ways the state exerts control over its population while biopower and discipline are tools employed for this end. Biopower is enacted over a whole population for management of mass health whether through living conditions, hygiene programmes, education and reproduction among others. Discipline, however, is aimed at individuals and keeps them in check by firmly delimiting what is and what is not acceptable behaviour. For Foucault $(1977,26)$ 'the body becomes a useful force only if it is both a productive body and a subjected body' and through regulation the state is able to achieve both. The Chilean state wants to regulate the reproductivity of its population and does so by disciplining those who resist legislation. While Foucault did not fully explore reproductive rights or reproductivity as biopolitics (Deutscher 2008) in this paper I discuss the Chilean state's power over women's reproductive rights as a form of biopolitical control with distinctly geographical implications in terms of their mobility across state borders. What this paper offers is an example of how governmentality and biopolitics are not confined to the territory of the state, instead control can be extra-territorial.

Chilean biopolitical control can be seen through the reproductive control of women's bodies whereby HIV positive Chilean women have been compulsorily sterilised and prohibited from having an abortion under any circumstance. Such population 'programmes', including enforced sterilisation, have been widespread across Latin America in the twentieth century (Craske 1999). Biological reproduction is central to the idea of a political citizen in a modern biopolitical state and particularly in one so dependent on machismo and these examples highlight how that power can be wielded. Ruth Miller (2007) has discussed the idea of the 'biopolitical womb' whereby women's wombs are the commodity of the government who can draw up laws and regulations for certain social engineering projects. As soon as a woman has a foetus growing inside of her the womb becomes a separate legal arena, taking precedence over the rights and decisions of the woman. 
Through the act of becoming pregnant women's bodies become subject to political discussions on life and death, race and nation, citizenship and motherhood, and the right to life of the foetus.

Government control clearly is not only wielded within state borders but the very act of crossing the border for an 'illegitimate' reason can provoke punishment. The border can thereby be seen as 'elastic', to borrow from Aldama (2002), as the act of crossing the border stays with the border crosser. A Chilean woman who procures an abortion in Peru is therefore not free of the state simply by leaving it; government control of her body is extraterritorial. While biopower is enacted over the whole Chilean population through reproductive legislation, it is discipline, or the threat of it, that shapes women's behavior. Dean (2010) has looked at how governing authorities aim to shape, regulate, control and turn behaviour into a specific end. However this desired end is not always reached due to resistance on the part of those being governed. Drawing on Foucault's $(1990,95)$ 'where there is power there is resistance', Death (2010) has argued that the concept of governmentality necessitates an interrelationship of power, freedom, and resistance. Resistance to biopolitical control need not be overt marches to parliament or public denunciation but can take individual, low-profile forms (Scott 1990). When women undergo an illegal abortion I argue they are performing the type of everyday resistance that Vinthagen and Johansson
(2013) argue is sought as a survival mechanism and also to undermine repression. Even when women are having abortions for their immediate need, they are still resisting Chilean biopolitical control.

\section{Reproductive Rights Across Borders}

This paper contributes to recent debates on the intersection of bodies, science, and the legal arena. The corporeal turn in feminist geography and the social sciences more broadly has refocused on the embodied individual and its relationship with nature, time, space, and other bodies (Fannin et al. 2014). Elizabeth Grosz's Volatile Bodies: Towards a Corporeal Feminism (1994) largely introduced and provoked feminist discussions of the body and feminist geographers have explored this by drawing on key theorists such as Luce Irigaray, Donna Haraway, Maurice Merleau-Ponty, Michel Foucault and many others. Important work has considered the messiness of the corporeal and the materiality of bodies (Longhurst 2001) as well as debating the extent to which feminism is 'biophobic' (Ahmed 2008, Davis 2009). Concurrently, work on reproductive technologies and cultures of procreation by Jeanette Edwards, Sarah Franklin, Margaret Lock and others has furthered the way we think about bodies, biomedical technologies and reproduction. This has resulted in a landscape where feminist work on the body can be taken seriously and reproductive technologies and mobilities have become a productive site of study. My research examines the changing 
mobilities of healthcare provision as legislation attempts to control bodily movement and how advancements in science and technology, such as medical innovation or transport improvements, impact this.

Certain reproductive trends such as adoption, fertility treatment, and surrogacy have become ever more globalised with technological and legislative advancements particularly benefiting those in the West. In recent decades cross-border reproductive care has risen globally, seeing families crossing borders for fertility treatments, often to fertility centres in countries with less restrictive regulations (Gunnarsson Payne 2013). Increasingly the freedom of mobility has become the luxury of the rich whereas the poor are ever more forced into fixity (Dalby 1999). This 'new reproductive mobility' provides opportunities for some and denies them for others. This mobility (or lack of it) has a clear geography; certain countries, states, cities or establishments become safe havens for women seeking abortions. There is a stark geographical unevenness to abortion provision most evidently due to variances in legislation between nation states but also within countries, one example being New Mexico where broader gestational age limits mean women travel from Mexico but also other US states for abortions (Landau \& Long 2015). The US-Mexico border has a history of women crossing for abortion, either American women seeking access to abortions in Mexico when access has been denied to them in their own country or
Mexican women seeking safe abortions in the US (Ojeda 2006, Angulo \& Guendelman 2002). Called elsewhere 'abortion tourism' (Sterling 1997) I would argue that this is problematic and erases the struggle, pain, shame and fear that traveling for abortions entails for many women. While this travel can be emancipatory it is not an option for all women and can even be accompanied by increased harm and violence as this paper will address.

Despite this research on the USMexico border the extent of travel for abortion between Latin American states remains vastly understudied and abortion border crossings between Chile and Peru continue unstudied. The Chile-Peru border is worthy of study due to the unusual geographical location of Arica, Chile's northernmost city. Arica is peripheral in numerous ways; separated from the rest of Chile by desert, socioeconomically deprived, and due to its proximity to Peru shares many cultural similarities with its northern neighbour. Arica is militarised due to its border location but also sees fluid movement across the border in terms of trade, drugs, and people and it is perhaps Arica's peripherality that allows and stimulates border crossings for abortions. Chile is notoriously heterogeneous and capital-centric, and Arica, 2000km away from Santiago, often goes ignored.

While I argue the Chile-Peru case is distinctive, parallels can be drawn between Chile and Ireland. Restrictive abortion laws in Ireland have resulted in a history of 
women traveling to Britain in search of the procedure. Approximations as to the number of Irish women seeking abortions in Britain vary but 2015 estimates suggest that at least ten women a day travel from Ireland to Britain for abortions (The Independent, June 9, 2015). Many more purchase abortion medication on the Internet and selfadminister. The main difference with the case of Ireland is that Irish women travel to Britain where safe, legal abortions can be found while Chilean women travel to Peru where abortions are still illegal in most cases and visit unregulated clinics of unknown quality. The other legal difference is that most Irish women, although notably not all (Side 2016), have legally won the right to travel abroad for abortions whereas this right exists for no-one in Chile. A third dissimilarity is that Irish women, regardless of their location within Ireland, are required to undertake a significant journey to Britain, across the sea. However, while most Chilean women cannot travel to another country easily and cheaply, those located in northern Chile can travel to Peru very quickly and affordably.

\section{Methodology}

The methods were dictated by the sensitivity of this research with larger scale data sets or surveys being inappropriate. Self-reporting surveys regarding abortion prevalence vastly underestimate the true number of abortions in countries where they are legal, giving doubt to their utility where the practice is illegal (Tourangeau \& Yan 2007). Moreover, this project was an exploratory exercise into the phenomenon of women crossing the border for abortions in order to highlight a brand new research area and stimulate further research on the topic, not about the incidence of abortions. Analysis through the lens of biopolitics allowed me to draw on a rich body of academic work conducted since Foucault introduced the term and was ideally situated to consider issues of health, government control, and the state.

Interviews with both medical professionals and those who travel for healthcare highlight the violent repercussions of healthcare legislation on women's bodies. This research emerged from nine in-depth interviews with healthworkers and one Chilean who had travelled to Peru for an abortion, whom I will call Ana Castillo. The interviews took place in Arica, Chile, between March and August 2014 usually in their place of work or at my university office. The interview with Ana Castillo took place in the home of a mutual friend. Having this mutual friend meant there was already a certain level of trust and rapport which is so vital for such research. Five additional shorter interviews were conducted at medical clinics in Tacna, Peru, in August 2014. Interviews were chosen as a method to provide depth and room for exploration of key issues and were supplemented by analysis of Chilean legal documents, policy documents, and media reporting to understand the wider situation 
of abortion in Chile and to better situate the interview findings.

Discussing sensitive topics entails the potential for risk but these risks can be mitigated when participants are given agency. When the participant can control what is discussed the interview can take place on their terms, within their comfort zone, and the discussion can even be beneficial for the participant (Corbin \& Morse 2013). Abortion was a difficult topic to address in Arica, and due to the taboo surrounding it some interviewees presumed I wanted to talk about miscarriages. However, since all but one of my interviews were healthcare professionals they had a sense of detachment which made talking about a sensitive issue possible. Participants were selected due to the roles they held in healthcare provision in northern Chile including at the municipal organisational level, within a university, and within clinics. Ideally I would have interviewed a greater number of participants but the illegal nature of abortion and the size and peripherality of Arica was a major limitation.

Consent forms made the details of participation clear, all names have been anonymised, and data is stored securely. Most interviews were audio recorded and then transcribed in Spanish with quotes translated to English by myself. This was not suitable for the interview with Ana Castillo and the shorter interviews in Tacna for which I made handwritten notes. These transcribed interviews were analysed during the research process to strengthen future interviews and then more substantially once all were transcribed. This analysis began with open coding which highlighted distinct concepts to develop more focused coding (Charmaz \& Belgrave 2002). This, alongside analysis of government documents, media reports, and secondary literature, resulted in refined categories with the overarching groups being the logistics of crossing the border, class, safety, and the legal situation in Chile. This paper will discuss each of these four categories combining interview findings and data from academic, government, and media sources.

\section{The Legal Situation of Abortion in Chile}

All interviewees spoke about the illegal nature of abortions in Chile due to the government's drastic and uncommon stance. Chile is one of the very few countries in the world with a total abortion ban but, unusually, has not always had a total ban. Once a vanguard of abortion liberalisation, abortions had been legal in some circumstances following the Health Code of 1931 and the medical community vastly improved women's rights with regards to reproduction throughout the 1960s and early 1970s. However, on $15^{\text {th }}$ September 1989 , Pinochet's military administration, on the eve of their departure from office, imposed draconian abortion laws making the practice illegal in every circumstance. Pinochet seized power in September 1973 but chose not to legally change the Health Code until his impending removal from power became 
inevitable. Despite the fact that between 1931 and 1989 therapeutic abortion to save the life or preserve the health of the mother was permitted, one of the main players in Pinochet's regime, Jaime Guzmán, vowed to eradicate therapeutic abortion claiming that women should instead choose to be martyrs and confront death for their unborn child (Casas Berreca 1997).

Pinochet defined the nation as a family consisting of La patria/la mujer (the female nation), el ejercito (the male army), and their offspring, the Chilean youth. Pinochet posited himself as the generous, benevolent, and strong father of this nationfamily. Under Pinochet Chile was a heterosexual, traditional nation led by the army and the ruling administration was fuelled by machismo in order to protect the nation from the menace of outside threats. Machismo is the stereotype of hypermasculinity associated with Latin American maleness that developed, argues Hardin (2002), due to Spanish conquistadors' reaction to indigenous gender and sexual expression. Pinochet embodied the supreme stereotype of Latin machismo; he was the authoritarian and all-powerful man who guaranteed stability and security at the price of liberty and human rights. Machismo's continued legacy in Chile has strongly shaped reproductive legislation and gender and sexual expectations.

Pinochet deemed abortions to be an unnecessary evil due to advances in medicine and also restricted women's access to contraception in the $1980 \mathrm{~s}$, a move that saw a rise in abortion (Paxman et al. 1993). Contraception is available in Chile but is expensive and while the morning after pill is also available not all pharmacies will sell it, citing religious reasons. Family planning is aimed predominantly at married women and the increasing privatisation of healthcare is furthering the difficulties of obtaining contraception for poorer Chileans. Moreover, according to healthworker Christian Hernández, many Ariqueño men resist using condoms. In a culture of machismo condoms are seen as emasculating, ineffective, and a barrier to pleasure and women's power to negotiate the use of condoms is limited. Women who use contraception are seen by some male partners as more likely to be unfaithful and contraception can be viewed as an impediment to the stereotypically insatiable macho male libido. The consequence is many unplanned pregnancies. This can be interpreted as a form of biopolitical control as from both legal and socio-cultural arenas women's sexual freedom and access to safe contraception are regulated, monitored and moralised.

Since Pinochet's stringent laws came into effect the relaxing of abortion legislation has been unsuccessfully attempted three times, in 1991, 2001, and 2006-07. Chile's current president Michelle Bachelet, a socialist physician, has made the most significant progress to date and the law is likely to be changed to allow abortions in three specific scenarios, itself a form of contestation. Bachelet acknowledged that 
the criminalisation of abortion has not led to fewer abortions and has only served to make them highly unsafe. According to Human Rights Watch (March 29, 2016) around 35 per cent of pregnancies in Chile terminate in abortions, corresponding to approximately 160,000 abortions per year, 64,000 of them by girls under eighteen. The vast majority of these women and girls will remain unaffected if the legislation changes under Bachelet's proposed 'three clauses' as in the words of Ana Castillo, the interviewee who had an abortion, 'there is no right to an abortion'.

Judicial punishment is a significant risk faced by these women since abortion in Chile is criminalised under articles 342, 343, 344 and 345 of the penal code as an 'illegal practice'. The punishment for having an abortion is three to five years imprisonment and 541 days to three years for those who perform an abortion. Penalisation of abortion does appear to be low in Chile, with only 1 per cent of women in hospital with complications being reported despite reporting being mandatory for Chilean medical professionals (Shepard \& Casas Becerra 2007). However, many women have still been penalised for having abortions in Chile and, when hospitalised, at a higher rate than in other Latin American countries. Despite this draconian legislation and threat of punishment that together create biopolitical control, many women still decide to seek an abortion and for some this means crossing the border. State disciplinary power goes beyond imprisonment which although very realistic is a rare occurrence. Biopolitical control extends to women's access to contraception, information that is available to them and as this paper will go on to discuss, their right to travel elsewhere for abortion services and medication that is available for them.

Abortion is clearly a contentious issue in socially conservative, Catholic Chile and individuals or groups appearing to promote the procedure come under severe criticism. Anti-abortion and pro-abortion marches and vigils are common across Chile, including in Arica. The dialogue between pro-life and pro-choice is literally taking place in the streets; figure one shows a poster with an image of a foetus, interestingly a symbol usually employed by pro-life groups, with the words 'this is not a human being'. A passer-by clearly disagreed with this message and scrawled under it in marker pen 'neither are you'. With official means of changing abortion legislation stalling at every attempt, activists employ alternative methods to show that not all Chileans agree with the status quo. Graffiti, an illegal act in itself, is used to spread information about abortions and resistance to Chilean legislation. 


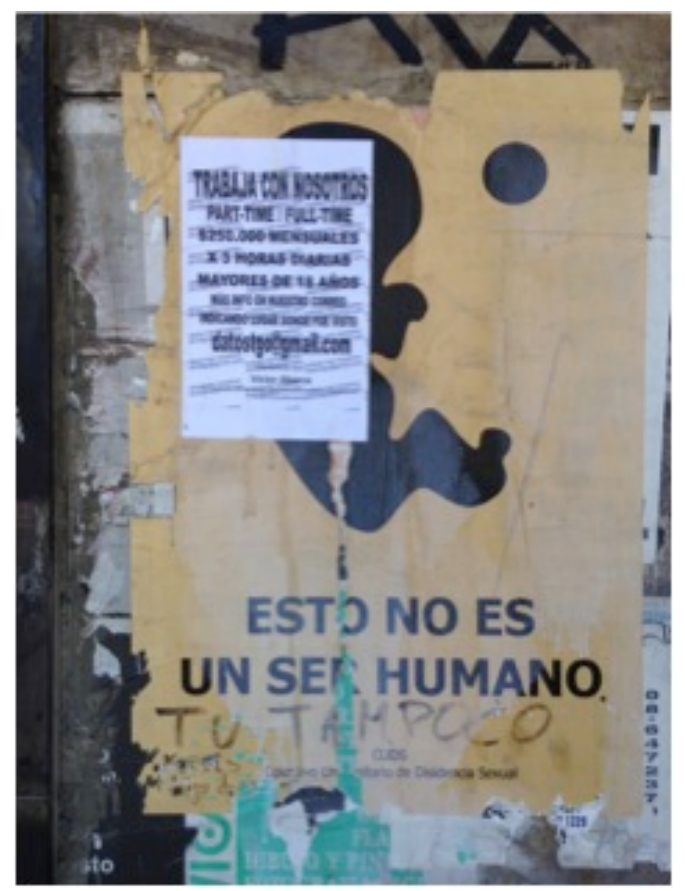

Figure 1: Pro-choice poster, Santiago, Chile. Author's photo

\section{Crossing the border}

The Chile-Peru border acts as a means of aiding healthcare provision for Chileans with an estimated 200 Chileans crossing the border to Tacna in Peru in order to visit the doctor, dentist, and optician every day. Ariqueños place great value on the medical attention that can be found in Tacna; Chileans say they are well treated, consultations are quick, with accurate diagnoses, and all at a low cost. Healthworker Christian Hernández stated that 'people travel to Peru for healthcare in abundance, I think our country is lacking in that area in terms of quality, cost and accessibility of healthcare'. Another healthworker, Valentina Araya, reported that Peru is popular for healthcare because it's cheaper than Chile, in Tacna's Hospital de la
Solidaridad Chileans can be seen by a doctor for just US\$4 and it's easier to book a consultation with a specialist. As Gabriela Torres, again a healthworker, recounted, resources in Chile tend to be concentrated in the central regions and so the whole of northern Chile lacks specialists meaning that citizens are forced to travel to Peru if they don't want to travel the distance to Santiago. She believes that a lot of Chileans would pay for these specialists were they to exist in the north but instead Tacna has both the specialists and the lower prices. These statements were supported by healthworker Florencia Espinoza who argued that the healthcare is of comparable quality either side of the border but the Peruvians win on price and speed. In Tacna multiple tests that would be spread out over weeks in Chile can be taken on the same day. While some Chileans feel a sense of unease in leaving their country for healthcare, there is in a general a prosperous flow of Chileans seeking services in Peru.

However, not all visits across the border for healthcare are for a health check or a new pair of glasses. The illegal and insecure nature of abortion in Chile forces women to seek non-official solutions to unwanted pregnancies. In the northernmost region of Chile, women are in the unique situation of having the opportunity to easily and quickly cross the border to Tacna in Peru, where abortion options are cheaper and more plentiful. Chileans in the rest of the country face longer and more expensive journeys if they chose to leave the country 
whether to Argentina, Peru, or further afield. It may seem surprising that women would choose to travel to Peru for an abortion where the procedure is still illegal except in case of the threat to the life or health of the woman. A woman that consents to an abortion can be sentenced to up to two years in prison while anyone who performs an illegal abortion can be sentenced to one to six years in prison in Peru. As healthworker Gabriela Torres explained; 'If a Chilean is found having an abortion with a provider in Tacna it is prison for the both of them'. However despite this, abortions are more accessible, cheaper, and punished less often than in Chile. Alejandra Flores suggests that women can find a level of anonymity in Peru that is almost impossible in Arica; 'it's more accessible, no-one asks any questions'. Due to the legal situation coupled with the taboo nature of the procedure, secrecy is paramount.

Another reason why women choose to travel to Peru is that the clinics that practice abortions are much more visible in Tacna than in Chile. They have clear signs outside offering solutions for 'late periods' [retraso menstrual], a term commonly known to be a codeword for clandestine abortions. Codewords allow practitioners to deny that they practice abortions but also illustrate how the topic is often indirectly referenced rather than explicitly given that many people, aside from healthworkers, recoil from terms such as 'aborto' [abortion]. This socio-cultural policing of the language and opportunities available to discuss abortion have real impacts on the information obtainable by women about their reproductive healthcare. The logistics of crossing the border therefore depend on inside knowledge. Due to abortion still being illegal in Peru women cannot use official channels to find an abortion provider and so recommendations tend to be word-of-mouth through informal networks. University healthworker Alejandra Flores stated;

'I think you begin to ask. 'Hey, do you know?' So for example if I had a friend who went. It starts with contacting the friend of a friend of a friend of a friend who says go to the market, to I don't know, whichever street, there you ask for a certain woman, she tells you it costs 200,000 pesos for example'.

Ana Castillo, who had herself undergone an abortion in Tacna told me how she knew where to go because her aunt knew the system; 'it's common knowledge, she was a direct source, she had taken people before, I knew I could trust her'. Ana was lucky enough to have financial and emotional support, her father paid the 100,000 peso fee (roughly US\$145), and her mother and boyfriend accompanied her across the border on the one-hour journey from Arica to Tacna. These largely female networks provide critical knowledge and information that is crucial to evade state biopolitical control. This highly personal act is embedded in a wider strategy of everyday 
resistance composed of individual travel, local solidarity, organised campaigns, and political lobbying.

A very common abortion method for Chileans in Peru is misoprostol, a medication suitable for ending early-term pregnancies. Misoprostol can be administered orally but is more effective when administered vaginally with a reduction in the need for surgical intervention and the quicker onset of abortion after administration. If complications do arise from using misoprostol, the results are indistinguishable from that of a natural miscarriage meaning that the women can seek medical treatment without fear. Scientific advancements have transformed access to abortion but have also complicated issues of legality. Technically misoprostol is legally available in Chile for the treatment of stomach ulcers but is only administered by healthcare professionals and cannot be obtained at pharmacies even for those with a prescription to avoid it being used for abortions. State control of abortion is so extensive and disciplinary power so comprehensive that even those suffering with stomach ulcers are affected. While it can be found on the mainly internet-based Chilean black market it costs US\$73-100, a lot of money for poorer Chilean women. It is therefore common for women to selfadminister the pill in Peru where it is cheaper and more accessible or smuggle it back into Chile. According to Women on Waves, a Dutch organisation that helps women access safe abortions, misoprostol 'is very difficult to get' in Chile whereas in Peru 'misoprostol is easily available under the brand names Cytotec and Misoprolen'. Healthworker Catalina López stated that medication for personal use is easy to bring across the border because guards at the checkpoint only examine large quantities while Valentina Araya recalled how when she was at university her friends would travel from Arica to Tacna to buy misoprostol cheaply. Misoprostol is therefore blurring the borders of abortion; the procedure need not be fixed in a geographical place which further impacts the extra-territorial dimensions of biopolitical control, the medication straddles the legal/illegal divide depending on what it is used for, and the appearance of a natural miscarriage blurs the line between intentional and unintentional loss of pregnancy.

The wider awareness and availability of misoprostol through the Chilean black market or from Peru has made abortions much safer with fewer deaths and serious health issues when administered correctly. These improvements in safety are supported by a women's collective who run a telephone hotline providing advice about misoprostol to women seeking abortions. The network run by 'Lesbians and Feminists for the Right to Information' launched in 2009 and has received more than 10,000 calls, up to 15 a day. These hotlines exist in most Latin American countries with restrictive abortion laws and are invaluable for women seeking information about safe 
abortions when the state denies such information (Drovetta 2015). Women can also find out information about using misoprostol safely though the aforementioned organisation Women on Waves, blogs, free online books, facebook groups, and through graffiti in public spaces. This type of activism and the way that feminist activists have formed networks of expertise markedly benefit poorer women in South America (McReynolds-Pérez 2017). These forms of alternative and underground communication are key to everyday resistance on a national scale.

\section{Class \& Abortion in Chile}

The legal situation regarding abortion does not affect all Chilean women equally. Abortion in Chile is as much about class as it is about gender. Illegality increases the cost of a safe abortion, meaning that in Chile - one of the most economically unequal countries in the world - a safe abortion is prohibited to many poorer women. Clandestine abortions are not necessarily unsafe but while a safe abortion in Chile can cost US\$500-1000 this is far beyond the means of many Chileans, forcing them to seek unsafe clandestine abortions, creating a distinction between poorer and wealthier women (Franceschet 2006). This has direct impacts on health as 3.8 per cent of urban non-poor women who undergo abortions in Chile are expected to require hospitalisation compared to 37.5 per cent of urban poor women (Singh \& Wulf 1994). Moreover, poorer women and girls in Chile are less likely to use contraception, thereby increasing the likelihood that they will become pregnant.

Abortion prosecution is thus discrimination on the grounds of poverty; middle and upper class women who can afford safe procedures are much less likely to suffer complications and find themselves in hospital. Poor women who have no other choice than to undergo high-risk, unsafe abortions are far more likely to require postabortion treatment in public hospitals where they can then be turned in to the authorities and prosecuted. Criminalising abortion does not prevent its occurrence but forces it underground making it unregulated, dangerous, and more expensive, disproportionately affecting poorer women. Biopolitical control means that if a woman attempts to take control of her own body she risks prosecution by the regulatory state.

Through interviews it became clear that this issue of class is less pertinent at the border because abortions in Peru are cheap and so accessible. This is especially pertinent because the northernmost region, Arica \& Parinacota, is one of the poorest regions in the country. Many women here would not be able to afford the costs of a safe, clandestine abortion in their own country. While women in the rest of Chile face either this expensive clandestine abortion or a significant, long, and expensive trip out of the country, women in Arica can be in Tacna, Peru, in an hour for a couple of dollars. Therefore, many types of 
women in Arica - students, mothers, and those who work full time - have the opportunity to travel cheaply and quickly for a foreign abortion that most Chileans are denied. This is what puts the north of Chile in such a unique national position. However, this opportunity comes with very real risks and concerns that are detailed in the following section.

\section{Safety of Clandestine Abortions}

Misoprostol has greatly improved the safety of abortions in Latin America yet abortions in Chile remain far more dangerous than their European counterparts; in the Latin America and the Caribbean Region the unsafe abortion mortality ratio is 10 times higher than that in Europe (WHO 2012). Complications arising from clandestine abortions are therefore the primary cause of maternal mortality in Chile (Blofield 2008). Irrespective of moral arguments or legislation, women will continue to have abortions and will continue to die from unsafe abortions. Biopolitical control can have deadly consequences. Valentina Araya reiterated how the government's stance on abortion is making a safe procedure, using medication, into an unsafe one:

'if the abortion medication is taken under the supervision of a doctor it's a good method but if you do it alone its very risky, but as it isn't permitted in Chile you'll never be able to do it under the supervision of a doctor'.
Clinics in Tacna can be run either by licensed physicians who specialise in abortions or by individuals without medical training. Women cannot be sure whether the procedure will be undertaken by a professional or a charlatan, making informal networks even more vital. The border thereby provides an opportunity in that an abortion becomes a viable option but it is an alternative that is hazardous and precarious. Abortions in Peru are regarded by some as commonplace and safe with Alejandra Flores stating; 'Of the few people I know who've been, no-one has had complications, as if they went for it over there and came back bleeding, they do it very well'. However, other views suggest differently, as Gabriela Torres said:

'I know it's a risk that the standards of hygiene there aren't the best, or so I have been told that they're scary places, but the situation is very... I don't know. People are dying to have an abortion in Tacna, it's not in the media, its not really spoken about. But everyone knows that people go to Tacna to do it'.

This echoes a general sense of distrust of Peruvian healthcare. Constanza Sepúlveda, a financially secure citizen of Arica, told me, 'I don't go for medical treatment in Tacna, I don't trust it. I go to my doctor here, if I can buy medicines cheaper there though I will buy them in Tacna'. Moreover, Daniel Valenzuela raised concerns about the safety of abortions carried out in Peru: 
'They're less regulated there, they don't have the best conditions but still people from here and other parts of the north want to go to Peru for abortions. Because they know that even if it isn't regulated, if it isn't the safest they still go because at least it's a possibility there... There a lot of people who go, to the places that aren't the best, they're clandestine, and after there are complications and they have to go with these complications to the health services in Chile'.

There are no available statistics regarding the number of abortions carried out and even healthcare professionals cannot estimate the number. Media outlets produce variable and inevitably unverifiable figures ranging from 50,000 to 300,000 clandestine abortions per year in Chile. Regional figures are even harder to estimate. Valentina Araya provided the following comment on Arica's border location in relation to abortions in Peru; 'there probably are more abortions in Arica with its proximity to Tacna but like I say, I don't know the national statistics, so I couldn't say for sure more or less, I just know that it's easier here'. The only information available is for situations when complications occur and Araya continued, explaining how when women need medical treatment for complications some doctors will report to the authorities while others will not. When doctors do report the problem the story finds itself in the local press, anonymised but usually with the woman's age and profession, along with a warning to readers that the Chilean penal code prohibits abortions. Disciplinary power can take these modest forms, infiltrating people homes through local media, a subtle reminder of the consequences of breaking the law.

Daniel Valenzuela declared that '[1]ast year [2013] here in Arica they saw to around 300 and something abortions, girls who had done the abortion in some clandestine way here or in Tacna and unfortunately some residue remained'. The vast majority of these cases did not result in prosecution and in 2012, 24 people were arrested for undergoing abortions nationally with none in Arica, while in 2013 in Arica two individuals were arrested for crimes relating to abortions out of 14 nationally. In 2014, 12 women were arrested for abortions, one of which was in Arica. No one was arrested in Arica in 2015 (Informe Anual Carabineros, 2012, 2013, 2014 \& 2015. Instituto Nacional de Estadísticas, Santiago). Punishment is therefore uncommon and even decreasing in Chile. This illustrates that to achieve biopolitical control it is not inevitably necessary to pursue judicial punishment against individuals, the threat of penalty and the forbidden nature of abortion is enough to regulate the lives and bodies of Chilean women, and the poorest women most of all.

The impacts to women's physical health are clear but it is also highly traumatic for women to be forced to commit an illegal act because an abortion is not legally available. This is a double trauma of 
having to make the decision to undergo the abortion but also to commit a crime. The lack of a right to choose forces them into criminality. Due to the illegality of the process women become vulnerable to other illegal activities, violence, and risky situations. One study of abortion in Chile by Casas Becerra \& Vivaldi (2013) found that three women interviewed were told that the abortion provider required oral sex as well as cash payment. Others tell of dillitage and cutterage without anaesthetic, unsanitary conditions, and botched abortions. Women cannot report these horror stories to the authorities for fear of being prosecuted for seeking to terminate their pregnancy. Sharon Pickering (2010) has highlighted how women who are forced to undertake extralegal border crossings can experience violence during the journey as well as at their destination. This also speaks to Aldama's (2002) aforementioned notion of the border being elastic, the border-crosser does not escape the border just by transgressing it physically, Chilean women seeking abortions in Peru are easily distinguished as vulnerable and more easily exposed to risks. Ana Castillo, regarding her own abortion recalled; 'obviously I was scared for my life, ay, it was awful, yeah I was terrified, it's like these are things that aren't legal you know, anything illegal is going to scare you because it's not safe, you can't go to someone if it goes wrong, you don't have that right'. She described that the overwhelming fear was for her physical safety but her family were concerned about legal repercussions, speaking in low voices, but in the gynaecology clinic 'everyone knows what happens there and they protect each other'. While incomplete abortions are the visible negative aftereffect with women ending up in hospital or even prison, the emotional impacts are much harder to grasp and deserve further study.

\section{Reflections: Biopolitics across borders}

In this paper I have highlighted an as yet unstudied phenomenon, women traveling from Chile to Peru for abortions, and undertaken preliminary analysis on it from a biopolitical perspective. The Pinochet military administration (1973-1990) saw women's bodies in Chile become increasingly regulated and controlled but the border provides an escape for women trapped by the state's prohibitive abortion legislation as they can travel to Peru for abortions. In this way, crossing the border becomes a space of resistance for Chilean women, a way to contest the restrictive laws on abortion. Usually undertaken out of desperation rather than as a subversive political act, through border crossings these women are nevertheless opposing the suffocation of their biopolitical agency by refusing to be the passive subjects of the state's reproductive control in a form of 'everyday resistance'. However, as this paper has demonstrated, biopolitical control extends beyond the edges of state borders, Chilean women found to have had an abortion in Peru can still be prosecuted under the Chilean penal code. The metaphor 
of the border as elastic thus becomes useful as legislation allows the state to wield biopolitical control up to and beyond its borders. Women choose to travel to Peru where abortions are cheaper, more accessible, and more anonymous but leaving Chile does not mean leaving Chilean legislation. Biopolitics thereby cannot be compartmentalised within states but transgresses national borders.

This border crossing is unlikely to cease any time soon. Even if the law does change to allow women access to legal abortion in three specific cases, the vast majority of women will remain unaffected. Women will continue to be forced to evade prosecution by the state even with the potentially fatal risks this involves. It is imperative that the dangers women are facing are recognised and examined. This study highlights the need for further investigation into the realities women face when making reproductive choices in Latin America and beyond.

\section{Acknowledgments}

This work was supported by the University of Nottingham School of Geography, the Developing Areas Research Group (of the RGS-IBG) travel prize and the RGS-IBG Dudley Stamp Memorial Award. Thank you to Mike Heffernan and Alex Vasudevan for your guidance with this research. Many thanks also to the comments of the three anonymous reviewers, this paper was greatly improved by your contributions.

\section{References}

Ahmed, Sara. 2008. "Open Forum Imaginary Prohibitions Some Preliminary Remarks on the Founding Gestures of the New Materialism'”. European Journal of Women's Studies 15 (1): 23-39.

Aldama, Arturo J. 2002. "Millennial Anxieties: Borders, Violence, and the Struggle for Chicana and Chicano Subjectivity". In Decolonial Voices: Chicana and Chicano Cultural Studies in the 21st Century, edited by Aldama, Arturo J., and Naomi Quinones p.11-29.

Bloomington: Indiana University Press Angulo, Veronica, and Sylvia Guendelman. 2002. "Crossing the border for abortion services: the Tijuana-San Diego connection". Health Care for Women International 23 (6-7): 642-653.

Blofield, Merike. 2008. "Women's Choices in Comparative Perspective: Abortion Policies in Late-Developing Catholic Countries". Comparative Politics 40 (4): 399-419

Casas Becerra, Lidia. 1997. "Women Prosecuted and Imprisoned for Abortion in Chile". Reproductive Health Matters 5 (9): 29-36.

Casas Becerra, Lidia, and Lieta Vivaldi. 2013. "La Penalización del Aborto como una Violación a los Derechos Humanos de las Mujeres". Informe Anual Sobre Derechos Humanos en Chile. Universidad Diego Portales: Santiago Charmaz, Kathy, and Liska Belgrave. 2002.

"Qualitative interviewing and grounded 
theory analysis". In The SAGE handbook of interview research, edited by Gubrium, Jaber p.675-694 London: Sage

Corbin, Juliet, and Janice Morse. 2003. "The unstructured interactive interview: Issues of reciprocity and risks when dealing with sensitive topics". Qualitative inquiry 9 (3): 335-354.

Craske, Nikki. 1999. Women and Politics in Latin America. Cambridge: Polity Press Dalby, Simon. 1999. "Globalization or Global Apartheid? Boundaries and Knowledge in Postmodern Times". In Boundaries, Territory and Postmodernity, edited by Newman, David p. 132-150

London: Cass

Davis, Noela. 2009. "New Materialism and Feminism's Anti-Biologism A Response to Sara Ahmed". European Journal of

Women's Studies 16 (1): 67-80.

Dean, Mitchell. 2010. Governmentality.

Power and rule in modern society. 2nd

edition. London: Sage Publications

Death, Carl. 2010. "Counter-conducts: A

Foucauldian analytics of protest". Social movement studies 9 (3): 235-251.

Deutscher, Penelope. 2008. "The inversion of exceptionality: Foucault, Agamben and 'reproductive rights'”. South Atlantic Quarterly 107 (1): 55-70.

Drovetta, Raquel Irene. 2015. "Safe abortion information hotlines: An effective strategy for increasing women's access to safe abortions in Latin America". Reproductive Health Matters 23 (45): 47-57.

Fannin, Maria, Julie MacLeavy, Wendy Larner, and Wenfei Winnie Wang. 2014.
"Work, life, bodies: New materialisms and feminisms". Feminist Theory 15(3): 261268.

Foucault, Michel. 1976. Society Must Be

Defended. Trans. David Macey. New York:

Picador

Foucault, Michel. 1977. Discipline and

Punish: The Birth of the Prison. Trans. Alan

Sheridan. New York: Vintage

Foucault, Michel. 1978. La

Gouvernementalite'. In Dits et Ecrits II.

Paris: Gallimard

Foucault, Michel. 1990. The history of sexuality: An introduction, volume I. Trans.

Robert Hurley. New York: Vintage

Foucault, Michel. 2003. Society Must Be

Defended. London: Picador

Franceschet, Susan. 2006. "Bachelet's Triumph and the Political Advance of Women". Nueva Sociedad 202: 13-22.

Grosz, Elizabeth. 1994. Volatile bodies:

Toward a corporeal feminism. Bloomington: Indiana University Press

Gunnarsson Payne, Jenny. 2013. "Reproduction in transition: cross-border egg donation, biodesirability and new reproductive subjectivities on the European fertility market". Gender, Place \& Culture: A Journal of Feminist Geography 22 (1): 107-122.

doi:10.1080/0966369X.2013.832656.

Hardin, Michael. 2002. “Altering masculinities: The Spanish conquest and the evolution of the Latin American machismo". International Journal of Sexuality and Gender Studies 7 (1): 1-22. 
Landau, Carmen, and Lisa Long. 2015.

"Under the Cover of Night: Abortion Across

Borders". MEDICC review 17 (4): 60-60.

Longhurst, Robyn. 2001. Bodies: Exploring

Fluid Boundaries. New York: Routledge

McReynolds-Pérez, Julia. 2017. "No

Doctors Required: Lay Activist Expertise

and Pharmaceutical Abortion in

Argentina”. Signs: Journal of Women in

Culture and Society 42 (2): 349-375.

Miller, Ruth. 2007. The Limits of Bodily

Integrity. Abortion, Adultery, and Rape

Legislation in Comparative Perspective.

Aldershot: Ashgate

Ojeda, Norma. 2006. "Abortion in a transborder context." In Women and Change at the U.S.-Mexico Border, edited by Doreen

J. Mattingly and Ellen R. Hansen, 53-69.

Tucson: University of Arizona Press

Pickering, Susan. 2010. Women, Borders, and Violence: Current Issues in Asylum, Forced Migration, and Trafficking. New York: Springer Science \& Business Media

Scott, James. 1990. Domination and the arts of resistance: Hidden transcripts. New

Haven: Yale University Press
Side, Katherine. 2016. "A geopolitics of migrant women, mobility and abortion access in the Republic of Ireland". Gender, Place \& Culture 23 (12): 1788-1799.

Singh, Susheela, and Deirdre Wulf. 1994. "Estimated Levels of Induced Abortion in Six Latin American Countries". International Family Planning Perspectives 20 (1): 4-13.

Sterling, Abigail-Mary. 1997. "European Union and Abortion Tourism: Liberalizing Ireland's Abortion Law'. The BC Int'l \& Comp. L. Rev. 20: 385-406.

Tourangeau, Rger, and Ting Yan. 2007.

"Sensitive questions in surveys".

Psychological Bulletin 133 (5): 859-883.

Vinthagen, Stellan, and Anna Johansson.

2013. “"Everyday resistance': Exploration of a concept and its theories". Resistance

Studies Magazine 1 (1): 1-46.

World Health Organization [WHO] (2012)

Unsafe abortion incidence and mortality

(Information Sheet) Retrieved from http://apps.who.int/iris/bitstream/10665/751

73/1/WHO_RHR_12.01_eng.pdf 